\title{
Desfiando memórias in exilium: Os trajetos dos intelectuais cubanos Carlos Franqui e Guillermo Cabrera Infante
}

\author{
Edinaldo Aparecido Santos de Lima ${ }^{1}$
}

FAVATTO JR., Barthon. Entre o Doce e o Amargo: Memórias de exilados cubanos, Carlos Franqui e Guillermo Cabrera Infante. $1^{\text {a }}$ ed., São Paulo: Alameda, 2014, v. 1, 310 p.

Lançado em 2014 pela editora Alameda, Entre o Doce e o Amargo, de autoria do historiador Barthon Favatto Júnior ${ }^{2}$, tem por meta apresentar uma leitura historicizada dos livros de memórias do jornalista Carlos Franqui (1921-2010) e do escritor e crítico cinematográfico Guillermo Cabrera Infante (1929-2005).

Neste livro, o leitor é convidado a acompanhar as trajetórias desses dois intelectuais cubanos que protagonizaram, por meio de suas ações e projetos, papéis relevantes para o enriquecimento do universo cultural de seu país. Ganha voz neste trabalho, temas que, na historiografia cubana oficial, são sumariamente abordados como, por exemplo, o exílio do intelectual cubano de esquerda e o estreitamento da política cultural na Ilha após 1959.

Além do mais, o autor dedica especial atenção as suas principais produções, como o jornal porta-voz do regime revolucionário, Revolución, e seu suplemento cultural, Lunes de Revolución. A propósito, o historiador percorre não apenas as causas que acarretaram no fechamento de Lunes e, posteriormente, do Revolución, como também explora as razões pelo desencantamento destes intelectuais com o regime de Fidel Castro e a opção pelo degredo na década de 1960.

Dividido em duas partes com dois capítulos em cada, o livro congrega organização cronológica e temática que contribui didaticamente para o entendimento dos processos históricos que envolvem suas vidas, pessoal e profissional, face a face com a Revolução.

\footnotetext{
${ }^{1}$ Mestrando do Programa de Pós-Graduação em História da Faculdade de Ciências e Letras da UNESP, Campus de Assis. Área de concentração - História e Sociedade; linha de pesquisa - Política: ações e representações..Bolsista da Coordenação de Aperfeiçoamento de Pessoal de Nível Superior (CAPES). E-mail: limasantos91@gmail.com

${ }^{2}$ Docente colaborador na área de História das Américas do Departamento de História da Universidade Estadual de Londrina (UEL), Barthon Favatto Júnior é licenciado (2003) em História pela Universidade Estadual Paulista (UNESP), onde também, em 2012, defendeu sua dissertação de mestrado. Atualmente, como doutorando na UNESP de Assis, o autor desenvolve pesquisa sobre fotografia e experimentalismo fotográfico cubano presente no Jornal Revolución entre os anos de 1959 e 1961.
}

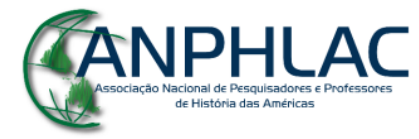

Revista Eletrônica da ANPHLAC, ISSN 1679-1061, №. 22, p. 383-387, Jan./Jun., 2017.

http://revista.anphlac.org.br 
Denominada Gênese, a primeira parte do livro abrange um momento de compreensão da origem intelectual dos autores nos anos precedentes à Revolução (1951-1959). Já na segunda parte do livro, intitulada Êxodo - cobrindo o período 19591968 -, apresentam-se as disputas político-culturais ocorridas na ilha no intuito de traçar as razões e os motivos que concorreram para que intelectuais outrora engajados com a Revolução Cubana, passassem a dissidentes da mesma.

Com uma sofisticada trama de estudos reconhecidos, capitaneados em diversos campos das ciências sociais, além da própria história, o autor, meticulosamente, pinça do cenário político cultural revolucionário, os principais dilemas e conflitos de uma geração de intelectuais cubanos que objetivavam construir uma nova acepção artística tipicamente cubana.

O historiador não apenas desembaraça minuciosamente, do emaranhado de narrativas de memória dos autores e do conjunto de fontes utilizadas, as causas que levaram esses escritores, compromissados com o processo revolucionário cubano, ao exílio, como também as articula a questões de cunho histórico, político, social e cultural que nelas estão imersas.

Na primeira parte do livro, destaca-se o capítulo "Da Revolução ao Revolución, sob o signo do Jeep de la Libertad". Neste, Favatto Jr. insere Carlos Franqui e Guillermo Cabrera Infante como partícipes engajados, cada qual ao seu modo, na luta revolucionária para destituir do poder o então governante, Fulgêncio Batista (19521959). Foi em meio a um contexto de luta popular, levada a cabo por diversos setores da sociedade cubana, que Carlos Franqui criou, em 1956, o jornal Revolución.

Consequentemente, com a derrocada de Batista, este periódico que então circulava clandestinamente logo se tornou o porta-voz impresso do Movimento 26 de Julho $^{3}$ (M-26/7). Com o objetivo de organizar, orientar e divulgar a ideologia revolucionária aos cubanos, o Revolución e a Radio Rebelde (outro meio de comunicação fundado em 1958 e dirigido por Franqui) foram as alternativas

\footnotetext{
${ }^{3}$ O Movimento 26 de Julho (M-26/7) foi uma organização política e militar cubana criada em 1953 por indivíduos, dentre eles o advogado Fidel Castro, que atuaram inicialmente em ataques aos quartéis do exército do ditador Fulgêncio Batista em Santiago de Cuba. Seguidores das ideias de José Martí, os membros do M-26 derrubaram o governo de Batista no dia 31 de dezembro de 1958. Devido à amplitude ideológica e a seus objetivos, o M-26 agregou jovens das mais diversas procedências políticas. Os primeiros membros do movimento, como Fidel Castro, Haydée Santamaría e Antonio Nico López, tiveram a colaboração de Che Guevara, Camilo Cienfuegos, Raúl Castro, Juan Almeida Bosque, Celia Sánchez, Huber Matos, Carlos Franqui entre outros. (FAVATTO Jr., 2014, p. 169)
}

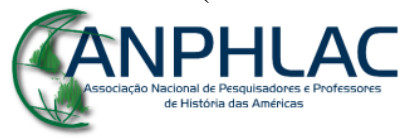

Revista Eletrônica da ANPHLAC, ISSN 1679-1061, №. 22, p. 383-387, Jan./Jun., 2017.

http://revista.anphlac.org.br 
clandestinas de comunicação que permitiram a toda Ilha o contato com os revolucionários durante a ditadura batistiana. Isto é, para Favatto (2014, p. 91), tanto o Revolución quanto a Radio Rebelde "não só amplificaram como concederam cor e timbre às vozes revolucionárias, principalmente àquelas isoladas pelas densas e até então quase incomunicáveis matas da Sierra Maestra."

Outro marco importante exalçado pelo autor emana da criação, ainda em 1959, do Lunes de Revolución ${ }^{4}$, cuja direção fora entregue a Guillermo Cabrera Infante. Esse suplemento cultural do jornal Revolución apresentou-se, imbuído de um espírito experimentalista, como defensor da pluralidade estética de esquerda e declaradamente crítico ao modelo soviético de socialismo.

$\mathrm{Na}$ segunda fase da obra, Favatto Jr. examina de maneira acurada tanto a ascensão quanto o declínio do conjunto de intelectuais que denominou "Grupo R". Formado por membros do Lunes e Revolución, esse conjunto de intelectuais emergia como ponta de lança do regime nascente. Embora fossem imbuídos de um espírito progressista e apoiassem a revolução, não escaparam críticas ao governo e ao modelo cultural soviético em seus trabalhos. O esfacelamento deste grupo, o autor atribui à proximidade de Cuba com a União Soviética. O efeito dessa relação acarretou numa reformulação interna dos quadros intelectuais e fez de outro grupo de intelectuais, mais alinhado aos ideais culturais soviéticos, condutor da cultura em Cuba. (FAVATTO Jr., 2014, p. 197)

Esmeradamente debatidos no último capítulo, os exílios de Guillermo Cabrera Infante e Carlos Franqui, na visão de Favatto Jr., decorreram de uma disputa intelectual que, iniciada antes da eclosão da Revolução Cubana, acirrou-se à medida que a aproximação política de Cuba com a União Soviética tornou-se imprescindível e passou a privilegiar outro grupo de intelectuais como vanguarda cultural do regime castrista. Aliás, mais do que a perda de visibilidade dentro do novo governo, outro fato que concorreu para o rompimento de Carlos Franqui e Guillermo Cabrera Infante, defendido pelo historiador, foi a perda gradativa de esperança desses intelectuais de algum dia estabelecer uma Revolução Cultural dentro da Revolução.

Frente à qualidade do trabalho investigativo, o livro, porém, apresenta uma ausência que, mesmo que pequena, por vezes, merece ser comentada. Ao se atentar às

\footnotetext{
${ }^{4}$ Para conhecer de maneira aprofundada a imbricada relação de Lunes de Revolución com a política cultural vigente em Cuba a partir de 1959 e a participação do intelectual cubano, ver: MISKULIN (2003).

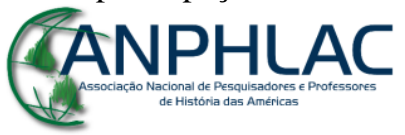

Revista Eletrônica da ANPHLAC, ISSN 1679-1061, №. 22, p. 383-387, Jan./Jun., 2017. http://revista.anphlac.org.br
} 
disputas por espaço na vanguarda cultural revolucionária, ou seja, de intelectuais e artistas que, de um lado, eram favoráveis às diretrizes soviéticas de cultura e, do extremo oposto, daqueles que a execravam, Favatto Jr. não se apercebe de outras críticas e disputas que rondavam, por exemplo, o suplemento Lunes.

Tal investida coubera aos dirigentes da editora El Puente, Isel Rivero e José Mario. Ambos acusavam o suplemento de privilegiar apenas a divulgação de obras de membros próximos a seu diretor, Guillermo Cabrera Infante, e de não abrir espaço para novos escritores. Nas palavras de Silvia Miskulin,

(...) a polêmica entre membros da editora El Puente e de Lunes de Revolución fazia parte não só da disputa entre escritores de distintas gerações, mas também da busca por ocupar os novos espaços culturais e institucionais surgidos após a Revolução. (MISKULIN, 2009, p. 53)

Com efeito, podemos notar que assim como os membros de Lunes atacavam os escritores da geração que o precediam, os jovens de El Puente procediam da mesma forma em relação aos participantes de Lunes. Sendo assim, percebe-se um ambiente convulsionado composto por múltiplos grupos intelectuais que ensejavam maior notoriedade na esfera cultural cubana, quiçá mais complexo do que foi arguido pelo historiador.

Em linhas gerais, por um lado, o êxito da Revolução Cubana, em 1959, descortinou grandes possibilidades de transformações na ilha, que ocorreram em todas as esferas da sociedade, inclusive na cultura. De acordo com a historiadora Aviva Chomsky, "a revolução democratizou e contribuiu para todas as áreas da cultura de uma maneira sem precedentes na história da América Latina." (CHOMSKY, 2015, p. 137) Por outro lado, a revolução controlou, censurou e restringiu a produção cultural a ponto de muitos autores e artistas, a exemplo de Guillermo e Carlos, e tantos outros, terem decidido se exilar.

Entre o Doce e o Amargo é uma contribuição de relevo para os estudos latinoamericanos. Alguns dos méritos do livro encontram-se na capacidade de contestar uma acepção oficial de história, por meio de memórias de intelectuais exilados, assim como de poder reavaliar o processo revolucionário por um viés historiográfico que abriga renovados questionamentos e desafios para pesquisadores das ciências humanas, sobretudo historiadores. Em síntese, o debate sobre a Revolução instaurada em janeiro

\section{GANPHLAC}


de 1959 ainda está longe de ser dado por encerrado. Por conta disso, precisamos voltar nossos olhares para compreender uma Cuba diversa, multifacetada, intrigante, confusa e dinâmica. Ao explorarmos os matizes de seu passado, permitimo-nos renovar criticamente nossa maneira de ver nossa própria realidade de outro ponto de vista.

\section{Bibliografia}

MISKULIN, Sílvia C. Cultura Ilhada: imprensa e Revolução Cubana (1959-1961). São Paulo: Xamã, 2003.

Os intelectuais cubanos e a política cultural da Revolução (1961-1975). São Paulo: Alameda, 2009.

CHOMSKY, Aviva. História da revolução cubana. São Paulo: Veneta, 2015.

\section{GANPHLAC}

